\title{
Ascertainment of myotonic dystrophy through cataract by selective screening
}

\author{
A Kidd, P Turnpenny, K Kelly, C Clark, W Church, C Hutchinson, J C S Dean, \\ N E Haites
}

\begin{abstract}
Myotonic dystrophy (DM) almost always results from the expansion of an unstable (CTG)n repeat. The mutation can be detected directly. Affected patients with cataracts may have minimal additional signs of the disorder, but all are at risk of life threatening complications. We have studied the efficacy of detecting new families with myotonic dystrophy by selectively screening cataract patients. Selection criteria were: age under 60 with no obvious precipitating factor (except non-insulin dependent diabetes mellitus (NIDDM)); patients of any age with other signs suggestive of myotonic dystrophy detected by the ophthalmologist.

Ninety-six patients were tested prospectively; 17 others under 55 were screened retrospectively. All patients were counselled by a clinical geneticist before testing. The patients' DNA was analysed using the DNA probe/restriction enzyme combinations GB2.6/EcoRI, KB1.4/BgII and polymerase chain reaction (PCR). Six patients have been found to have a mutation, three $(3 \cdot 1 \%)$ in the prospective group and three $(17 \cdot 6 \%)$ in the retrospective group. Three of these patients had minimal myotonic dystrophy and three had classical DM.
\end{abstract}

(f Med Genet 1995;32:519-523)

Dystrophia myotonica is the most common form of adult muscular dystrophy and has a prevalence of 1:7610 in the Grampian region of Scotland. ${ }^{1}$ It is an autosomal dominant multisystem disorder. The classical clinical features include myotonia, progressive weakness and wasting of distal limb and face muscles, cataracts, and frontal balding. However, the clinical features are very variable, ranging from asymptomatic to the severe congenital form. Affected patients are at increased risk of life threatening cardiac arrhythmias and general anaesthetic complications. ${ }^{2} \mathrm{DM}$ shows marked anticipation; the disorder usually has earlier onset of symptoms and becomes increasingly severe with each successive generation. ${ }^{34}$

The association with cataract has been recognised since 1911. Fleischer, ${ }^{3}$ in 1918, recognised that different branches of DM families were often connected through people with cataract but with no obvious muscle disease. Vogt, ${ }^{5}$ in 1921, first described the polychromatic iridescent particles and rosette-like subcapsular opacities which are highly characteristic of DM. However, mature cataracts in DM are indistinguishable from advanced senile cataracts. $^{6}$

The mutation causing DM almost always appears to be an expansion of a (CTG)n trinucleotide repeat in the $3^{\prime}$ untranslated region of the myotonin protein kinase gene located on chromosome $19 \mathrm{q} 13.3 .^{7-12}$ Unaffected people have from five to 37 copies of the repeat; affected subjects have from 50 to over 2000 copies. ${ }^{12}$ The mutation can be detected directly using Southern analysis or PCR, depending on the number of copies. The number in blood lymphocytes correlates roughly with the severity of the disease and the age of onset. ${ }^{13}$

Ophthalmic examination has long been an integral part of the diagnostic assessment for DM, but few new DM families are ascertained through the eye department. ${ }^{6}$ Direct mutation analysis now allows the identification of minimally affected patients with DM, presenting only with cataracts. Our objective was to estimate the effectiveness of ascertaining new families with DM by selectively screening cataract patients in order to detect minimally affected DM cases and unrecognised classically affected cases.

We concentrated our study mainly on the younger age group because cataracts are extremely common in the elderly.

\section{Methods \\ SUBJECTS}

One hundred patients were invited to enter the study prospectively. All of the patients were recruited from the Aberdeen Royal Infirmary (ARI) Ophthalmology Department between April 1993 and June 1994. They all lived in the Grampian region or in the Shetland and Orkney islands. All were white except for one Indian and one Nigerian. The selection criteria were as follows.

(1) Unilateral or bilateral cataract in patients under 60 years of age, except those with a definite history of trauma, uveitis, type 1 diabetes mellitus or with a known family history of DM. Those with NIDDM were not excluded, as this is a recognised complication of DM.

(2) Cataracts characteristic of DM (iridescent/ polychromatic crystals seen by slit lamp anywhere in the lens), white fluffy posterior subcapsular opacities or any other unusual cataracts in patients of any age.

(3) Other ophthalmic or non-ophthalmic signs of DM noticed by the ophthalmologist in 


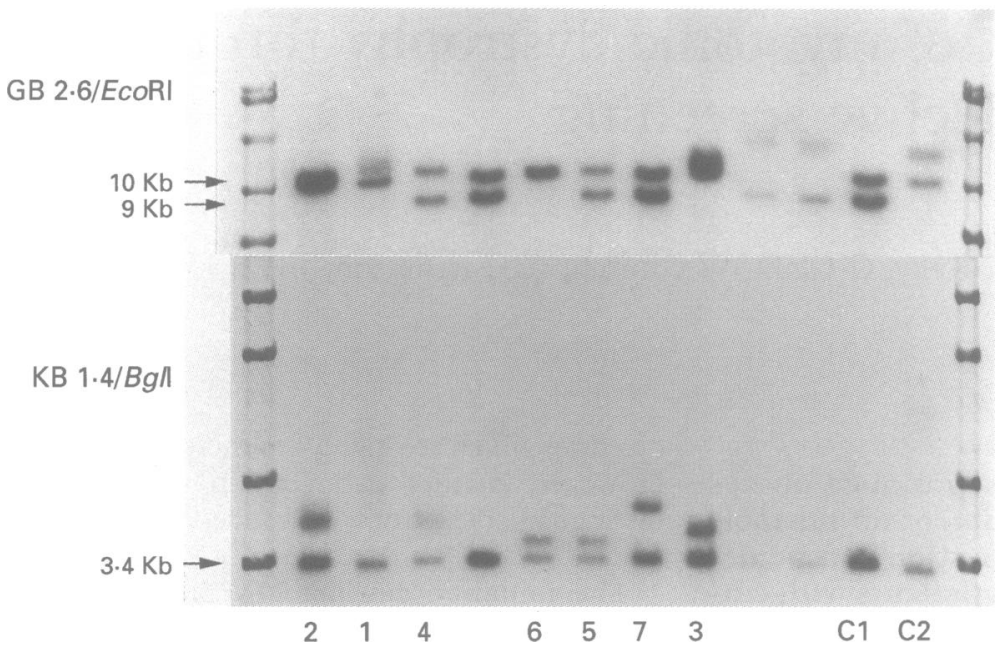

Figure 1 Two Southern blots of EcoRI digested genomic DNA probed with GB2.6 and BglI digested genomic DNA probed with KB1.4 from cases 1 to 7 . Numbers correspond to case numbers in text and in table $2 . C 1$ is the normal control, $C 2$ is the myotonic dystrophy control. Case 7 is the Nigerian with a probable polymorphic variant.

patients of any age in the absence of a known family history.

Another 23 patients who had cataract surgery at less than 56 years of age were selected by our ophthalmologists from their database. The same criteria, except for age, were applied for selection.

The patients in the prospective group were given an information sheet about DM and were counselled and examined by a clinical geneticist. Informed written consent was obtained before blood was taken for DNA analysis. Four patients declined to enter the study.

Those identified retrospectively were sent the information sheet and invited to attend a genetics clinic. Seventeen of the 23 patients attended and agreed to enter the study. Those from both groups with negative results were informed by post; those with positive results were invited back for further counselling and investigation. Counselling was offered to other family members through the index case in the usual way.
Table 1 Results

\begin{tabular}{lll}
\hline Ages & Prospective & Retrospective \\
\hline Ages at onset of symptoms & & \\
$\quad$ Mean age & $48 \mathrm{y}$ & $43 \mathrm{y}$ \\
$\quad$ Age range & $8-72 \mathrm{y}$ & $28-53 \mathrm{y}$ \\
Ages at cataract surgery, 1st eye & $51 \mathrm{y}$ & $46 \mathrm{y}$ \\
$\quad$ Mean age & $20-71 \mathrm{y}$ & $31-55 \mathrm{y}$ \\
$\quad$ Age range & & \\
Sex & $48(3)$ & $7(0)$ \\
Female & $48(0)$ & $10(3)$ \\
Male & $9(0)$ & 0 \\
Possible precipitating factors & $10(0)$ & $1(1)$ \\
NIDDM & $5(0)$ & $2(0)$ \\
Steroid use & $3(0)$ & $1(0)$ \\
Possible trauma & $1(0)$ & 0 \\
Other eye disease & & \\
Alport's & $27(0)$ & $3(0)$ \\
Cataracts & $69(3)$ & $14(3)$ \\
$\quad$ Unilateral & $96(3)$ & $17(3)$ \\
Bilateral & $3(3 \cdot 1 \%)$ & $3(17 \cdot 6 \%)$ \\
Totals & & \\
Mutation present &
\end{tabular}

$\mathrm{O}=$ Number with mutation

\section{MOLECULAR ANALYSIS}

DNA was extracted from $10-20 \mathrm{ml}$ of blood by standard techniques. Patient DNA was digested with a fourfold excess of $E c o$ RI or $B g l I$ and run overnight on $0.9 \%$ agarose gels at $30 \mathrm{~V}$. The digested DNA was blotted onto Hybond $\mathrm{N}+$ using $0.4 \mathrm{~mol} / 1 \mathrm{NaOH}$ on an LKB Vacugene blotter. Filters were prehybridised overnight at $65^{\circ} \mathrm{C}$ in a Techne hybridisation oven. The prehybridisation solution was as described by the manufacturer for Hybond $\mathrm{N}+$ and $10 \mu \mathrm{l}$ sheared human DNA $(5 \mathrm{mg} / \mathrm{ml})$ was added to $20 \mathrm{ml}$ prehybridisation solution. The probes GB2.6 (for EcoRI digested $\mathrm{DNA}^{9}$ and $\mathrm{KB} 1.4$ (for $B g l$ digested $\mathrm{DNA}^{14}$ ) were labelled by random priming and hybridised to the filters for 16 to 24 hours. The filters were washed at $65^{\circ} \mathrm{C}$ in (A) $2 \times \mathrm{SSC}$, (B) $2 \times \mathrm{SSC}, 1 \% \mathrm{SDS}$, (C) $0.1 \times$ SSC for 10 minutes each wash. Autoradiography periods were from 24 to 48 hours at $-70^{\circ} \mathrm{C}$.

Molecular weight marker lanes were included on every gel probed with GB2.6 or KB1.4. Calibration curves were prepared by plotting log molecular weight against distance migrated in $\mathrm{cm}$. Where appropriate, mutation sizes were estimated from the calibration curves

Table 2 Affected patients' details

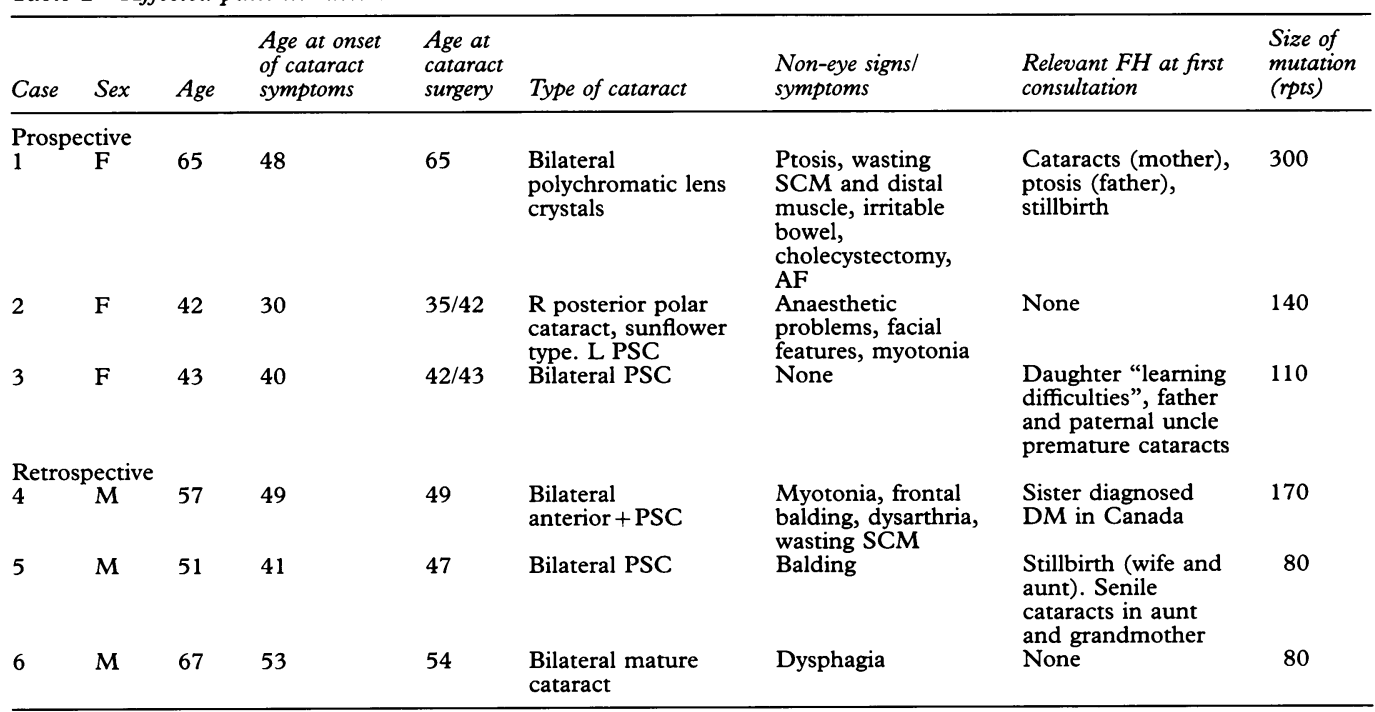

PSC $=$ posterior subcapsular cataract. $\mathrm{SCM}=$ sternocleidomastoid muscle $. \mathrm{AF}=$ atrial fibrillation 
Table 3 Details of cataract

\begin{tabular}{lll}
\hline & Non-DM cases & DM cases \\
\hline Unilateral cataract & 30 & 0 \\
Bilateral cataract & 77 & 6 \\
FH of cataract & $44(41 \%)$ & 4 \\
In 3 or more relatives & $5^{*}$ & 2 \\
In 2 relatives & $3^{*}$ & 2 \\
Types of cataract (as recorded in notes) & 55 & 2 \\
Posterior subcapsular (PSC) & 4 & 0 \\
Cortical & 13 & 1 \\
Mature & 0 & 1 \\
Posterior and anterior subcapsular & 0 & 0 \\
PSC and posterior polar sunflower & 5 & 1 \\
Unilateral polychromatic lens crystals & 5 & 0 \\
Bilateral polychromatic lens crystals & 1 & 0 \\
PSC and white opacities & 4 & 0 \\
Congenital & 22 & \\
No details & & \\
\hline
\end{tabular}

${ }^{*}$ Excluding congenital cataract.

and the approximate number of repeats was stated.

Patients with at least one $10 \mathrm{~kb}$ allele with $E c o R I$ and bilateral cataracts were also analysed by PCR to exclude a very small mutation. PCR analysis used primers 101 and 102 flanking the trinucleotide repeat. ${ }^{10}$ Approximately $20 \mathrm{ng}$ of
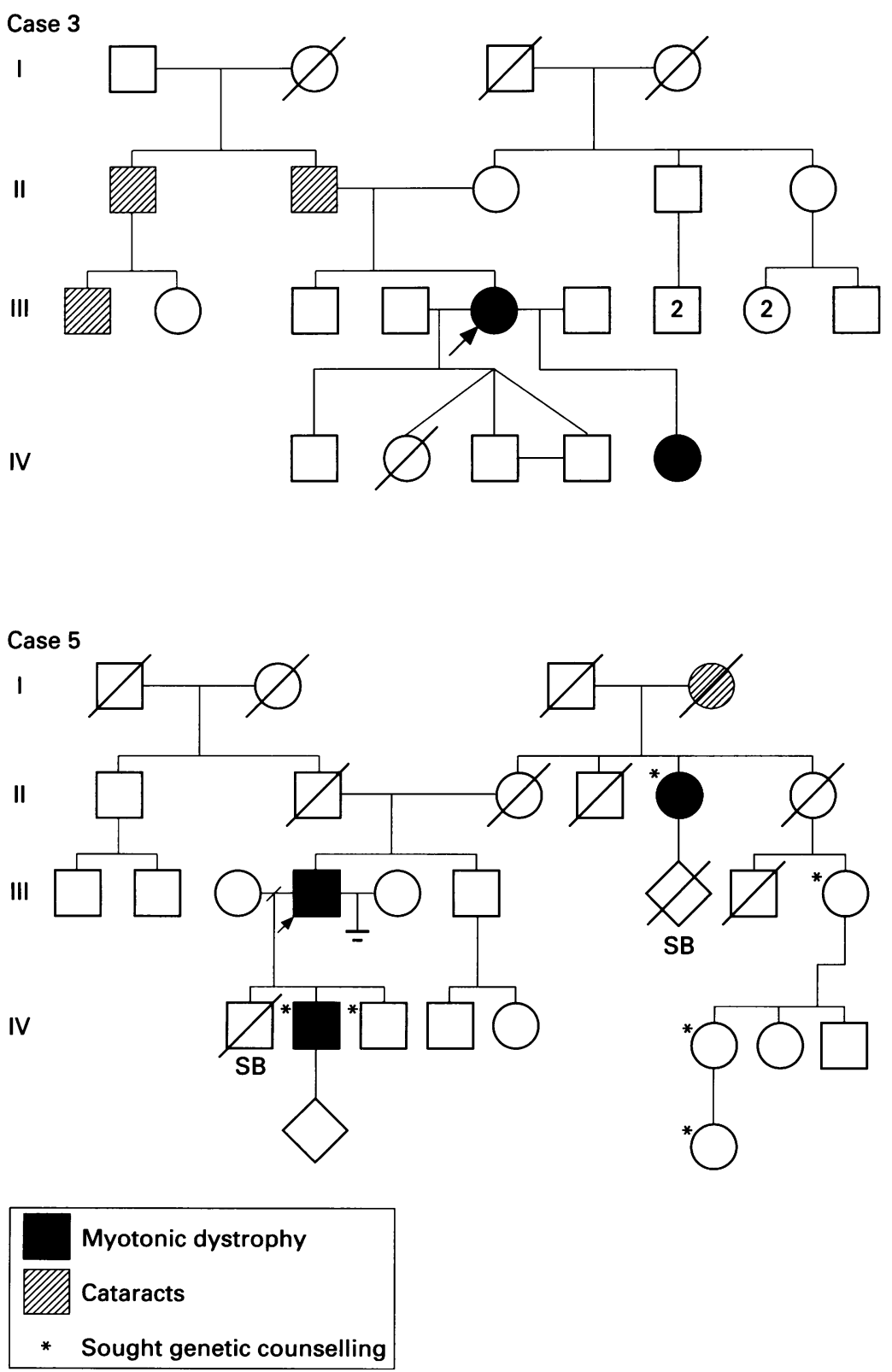

Figure 2 Pedigrees of cases 3 and 5. genomic DNA was amplified in the presence of $\alpha^{32} \mathrm{P}$ dCTP under similar conditions to those described by Brook et $a l^{10}$ and Mahadevan et al. ${ }^{11}$ One tenth of PCR product was run on $6 \%$ denaturing polyacrylamide gels for two to three hours at $2 \mathrm{kV}$. M13 DNA sequence was used as a size standard. After electrophoresis, the gels were dried and autoradiography was carried out overnight at room temperature.

Abnormal results were reanalysed with a fresh blood sample if the patient had few or no symptoms of DM beyond their cataract. One sample was also analysed using $\mathrm{KB} 1.4$ and BamHI.

\section{Results}

Table 1 summarises the ages, sex incidence, and precipitating factors in the two groups. Six mutations were found, three $(3 \cdot 1 \%)$ in the prospective group and three $(17.6 \%)$ in the retrospective group.

The probe/enzyme combination GB2.6/ $E c o$ R detected the largest mutation of $900 \mathrm{bp}$, whereas $\mathrm{KB1.4/BglI}$ detected the other five mutations (fig 1). Only one of the six mutations was detected by PCR analysis.

No cases were detected by PCR alone. The rest of the PCR alleles on 116 normal chromosomes ranged from 5 to 30 repeats and the frequency of different alleles within the normal range did not appear to differ from that of the normal white population.

A seventh case, from Nigeria, appeared to have a 500 bp expansion with KB1.4/BglI, but had two normal alleles of seven and 18 repeats on PCR. He had normal bands with EcoRI and $B a m \mathrm{HI}$. He had cataract surgery when aged 42 and 44, mild frontal balding, and very slight bilateral ptosis but no firm clinical evidence of DM.

Table 2 summarises the clinical characteristics of the six positive cases and the family history at initial presentation. Three cases had classical DM and had mutations estimated to be of 300,170 , and 140 repeats. A further three cases had minimal symptoms and signs beyond their cataracts and had mutations estimated to be around 110,80 , and 80 repeats.

None of the affected cases had NIDDM. One of them had been on steroids for glomerulonephritis, but there were no other known precipitating factors in any of the affected cases. Table 3 summarises details of the cataracts in the study group.

The affected cases had 25 living first degree relatives, seven of whom have come forward for counselling and testing so far. The 9 year old daughter of case 3 had learning difficulties, first noticed when she started school at the age of 5 . She had no history suggesting congenital $D M$ and no other signs of the disorder apart from poor coordination. She had a 900 triplet repeat expansion (fig 2).

The son of case 5 was counselled at another centre and had mild myotonia, muscle weakness, and a 330 repeat expansion (fig 2). The 81 year old maternal aunt of case 5 had senile cataracts and her only pregnancy ended in stillbirth. She has a 200 bp expansion. 


\section{Discussion}

These results show that there is a high frequency of undiagnosed DM in patients with presenile cataracts; $3.1 \%$ of patients in the prospective group and $17.6 \%$ of those in the retrospective group were found to have DM mutations. The high frequency in the retrospective group is probably a reflection of the small numbers (17 patients) tested and a degree of selection bias. It is possible that patients who recognise their own symptoms from our information leaflet may have been more likely to attend. There was also a lower age limit in the retrospective group ( 55 instead of 60 years).

Three of our six affected cases had classical DM. In two, during follow up after cataract surgery, the ophthalmologists' increased awareness of DM led to clinical diagnosis and referral to the genetic clinic. The other case with classical DM, case 4, suspected the diagnosis himself after his sister had been diagnosed in Canada five years ago. However, he had never told his GP or his hospital doctors of his suspicions. The minimally affected cases provided an opportunity to examine how the repeat size and clinical features are passed on in families ascertained through minimally affected subjects, thus avoiding the usual ascertainment bias of detecting families through classical or congenital cases only. Only two of the three had had offspring; case 3 (fig 2), a 43 year old woman with no symptoms beyond her cataracts, had a daughter with childhood onset of the disease. The repeat expanded from 110 repeats to 900 repeats in her daughter. Case 5 (fig 2) had a mutation size of 80 repeats; his son had 370 repeats and was classically affected. These two examples are typical of the degree of anticipation previously reported in this disease. There are two benefits of ascertaining families in this way. Firstly, the mutation is picked up earlier in its evolution through the family, allowing more scope for early diagnosis in other family membsrs and increased reproductive choice for those carrying the mutation, including the option of prenatal diagnosis. Secondly, a minimally affected index case may be better motivated to alert the rest of his family to the problem than a more severely affected patient. Case 5 was particularly diligent in this respect; two of his first degree relatives and four other relatives have already sought genetic counselling in different centres in England. The minimally affected cases themselves may be at risk of life threatening cardiac and anaesthetic complications and so all of the patients were advised to have annual electrocardiography and to wear Medi-Alert bracelets or to carry a Myotonic Dystrophy Alert card.

\section{A NEW WEST AFRICAN POLYMORPHISM?}

In Nigeria there has only been one published case of DM. ${ }^{15}$ Investigation of case 7 showed a $3.9 \mathrm{~kb}$ fragment in DNA digested with $B g l \mathrm{I}$ and probed with $\mathrm{KB1} 1.4,500 \mathrm{bp}$ larger than the "normal" fragment detected in Europeans. When his DNA was digested with $\operatorname{BamHI}$, KB1.4 detected a normal sized fragment.
GB2. 6 also detected a normal sized fragment following $E c o$ RI digestion of his DNA. PCR showed two alleles in the normal range. Thus, he does not have the triplet repeat expansion usually associated with myotonic dystrophy. It seems likely that the $3.9 \mathrm{~kb}$ fragment seen with $\mathrm{KB} 1.4 / B g l \mathrm{I}$ represents a restriction fragment length polymorphism. Unfortunately, the patient declined further investigations to confirm his unaffected status. A similar restriction fragment length polymorphism, resulting in a $3.7 \mathrm{~kb}$ fragment, has been reported in normal South African Bantus. ${ }^{16}$

The ancestors of case 7 originated from West Africa (Yoruba) and Ethiopia. His apparent polymorphism appears distinct from the South African Bantu polymorphism and has not been reported before.

\section{THE NATURE OF THE CATARACTS}

The cataracts were bilateral in all those carrying the DM mutation, in keeping with previous studies of DM cataracts. ${ }^{17}$ Only one of the six had the classic iridescent polychromatic lens opacities associated with DM. Ten other unaffected patients had similar "typical" lens changes; in five they were unilateral and in five they were bilateral. This supports previous studies showing that the so-called "typical" changes are not specific for DM, particularly when unilateral. ${ }^{18}$

A family history of cataract was present in $44 \%$ of the non-DM cases. In at least five families it appeared to follow autosomal dominant inheritance. In one, anticipation was evident. The results of the PCR analysis of the nonDM mutation carrying chromosomes suggest that cataract patients' PCR alleles are no different from those of the normal population.

A recent study of 106 unselected patients in Cardiff did not detect any patients carrying a DM mutation. ${ }^{19}$ Cataracts are, however, extremely common in the elderly population, with a prevalence of $41 \%$ in the over 60 age group in a white population. ${ }^{20}$ Considered together, the results of the studies suggest that screening would be most productive if confined to the younger age group and only extended to the older age group if there were other factors suggestive of DM.

\section{Conclusions}

We conclude that selective screening of cataract patients is an effective means of ascertaining new DM families. We would recommend considering screening for: (1) patients under 55 years with bilateral cataracts and no obvious precipitating factors other than NIDDM, (2) patients of any age with bilateral polychromatic crystals.

Using the above criteria, we would only have screened 49 patients prospectively and 14 retrospectively, but would still have detected the six mutations.

This work was supported by a grant from the Aberdeen Royal Hospital NHS Trust. We are also grateful for the help of the subjects who took part. 
1 Turnpenny $\mathrm{P}$, Clark $\mathrm{C}$, Kelly $\mathrm{K}$. Intelligence quotient in myotonic dystrophy, intergenerational deficit, and cor$300-5$.

2 Hawley R, Milner M, Gottdiener J. Myotonic heart disease. Neurology 1991;41:259-62.

3 Fleischer B. Uber myotonische dystrophia mit karaki. Arch Klin Ophthalmol 1918;96:91-133.

4 Howeler CJ, Busch HFM, Geraldis JPM, Niemeijer, MF, Steal A. Anticipation in myotonic dystrophy: fact or fiction? Brain 1989;12:779-97.

5 Vogt A. Die cataract bei myotonische dystrophie. Schweiz Med Wochenschr 1921;29:669-74.

6 Harper PS. Myotonic dystrophy. 2nd ed. London: Saunders, 1989.

7 Harley HG, Brook JD, Rundle SA, et al. Expansion of an unstable DNA region and phenotypic variation in myotonic dystrophy. Nature 1992;355:545-6.

8 Buxton J, Shelborne P, Davies J, et al. Detection of an unstable fragment of DNA specific to individuals with myotonic dystrophy. Nature 1992;355:547-8.

9 Aslandis C, Jansen G, Amemiya C, et al. Cloning of the essential myotonic dystrophy region and mapping of the putative defect. Nature 1992;355:548-51.

10 Brook JD, McCurroch ME, Harley HG, et al. Molecular ook D, McCurroch ME, Harley HG, et al. Molecular basis of myotonic dystrophy due to expansion of a trinucleotide CTG repeat at 3 end of a transcript encoding

11 Mahadevan M, Tsilfidis C, Sabourin L, et al. Myotonic dystrophy mutation due to an unstable CTG repeat in the $3^{\prime}$ untranslated region of the gene. Science 1992;255: $1253-5$

12 Brunner $H$, Nillesen $W$, Van Oost B, et al Presymptomatic diagnosis of myotonic dystrophy. $\mathcal{F}$ Med Genet 1992;29: diagnosis

13 Harley $\mathrm{H}$, Rundle S, Macmillan J, et al. Size of the unstable CTG repeat sequence in relation to phenotype and parental transmission in myotonic dystrophy. Am f Hum

14 Shelborne P, Winqvist R, Kunert E, et al. Unstable DNA may be responsible for incomplete penetrance of the myotonic dystrophy phenotype. Hum Mol Genet 1992;1:467-73.

15 Ashizawa T, Epstein $\mathbf{H}$. Ethnic distribution of myotonic dystrophy gene. Lancet 1991;338:642-3.

16 Goldman A, Ramsay A, Jenkins T, et al. Absence of myotonic dystrophy in southern African Negroids is associated with a significantly lower number of CTG trinucleotide repeats. f Med Genet 1994;31:37-40.

17 Asizawa T, Hejtmancik J, Perryman M, et al. Diagnostic value of ophthalmological findings in myotonic dystrophy. Am $¥$ Med Genet 1992;42:55-60.

18 Reardon W, McMillan J, Myring J, et al. Cataract and myotonic dystrophy: the role of molecular diagnosis. $\mathcal{f}$ myotonic dystrophy: the rol

19 Harley HG, Phillips MF, Shaw AM, et al. No increase in the frequency of the myotonic dystrophy mutation in
an unselected series of cataract patients. 7 Med Genet an unselected

20 Das BN, Thompson JR, Patel R, et al. The prevalence of age related cataract in the Asian community in Leicester: a community based study. Eye 1990;4:723-6. 